\title{
Margherita Sarfatti y el fascismo. La importancia de su origen judío y los costos de una identidad no deseada
}

\author{
Margherita Sarfatti and fascism.
}

The importance of his Jewish origin and the costs of an unwanted identity

Dr. Adolfo Kuznitzky

fitok@arnet.com.ar

Centro de Investigación y Difusión de la

Cultura Sefaradi (CIDiCSef)

Argentina

\section{Resumen}

Hablar de Margherita Sarfatti es hacerlo también del fascismo italiano que la tuvo como testigo privilegiada de su génesis y del encumbramiento de su líder, Benito Mussolini, y como autora de una muy difundida mundialmente biografía apologética del mismo. Al mismo tiempo, ella simboliza como nadie la errática trayectoria de ese movimiento político con respecto a Gli Ebrei d“Italia, (Los hebreos de Italia) de los que descendía, algo que olvidó, lo que no impidió persecuciones, temores y exilios y hasta la muerte de una hermana deportada a Auschwitz, pese a que en algún momento alcanzó tal importancia como cuadro político intelectual del fascismo que fue oficialmente recibida, en su representación, por el presidente de los Estados Unidos, Roosevelt.

Palabras clave: Hebreos de Italia - Fascismo - Identidad - Judeidad - Escape Conversión.

\section{Abstract}


Speaking about Margherita Sarfatti means speak about italian fascism too, she was also a privileged witness of its génesis and rise of its leader, Benito Mussolini, and as author of a widely apologetic biography of him.- At the same time she was as nobody else the erratic symbol in this politic movement about Gli Ebrei D' Italia (The Jews in Italy) in which case she was descending of them, something that she forgot, in spite of all, it did not prevent persecution, fear and exile and the death of a sister deported to Auschwitz, thought at the same point became so important as intellectual political fascism's leader that was officially received by the United State President, Mr. D.Roosevelt.

Keywords: Hebrews Italy - Fascism - Identity - Jewishness - Escape - Conversion.

“...Después de esa conversación me pregunté, por ejemplo, cuánto del mito de la romanidad fue harina del costal de Mussolini o fue más bien de la influencia de la Sarfatti. No conocí a una persona más enferma que ella de romanidad...”. De Felice, Renzo. Entrevista sobre el fascismo, p.20.

\section{Distintas denominaciones}

Pocos personajes históricos, dado que aún no se ha podido determinar con cierta precisión el rol que desempeñó en el fascismo, han tenido tantas y diversas denominaciones para calificarla como Margherita Sarfatti. Así, por ejemplo, uno de los apelativos recuerda su pasado socialista -vergine rosa (virgen rosa) en alusión a la heroína de la Comuna de París-; otro le atribuye aptitudes mágicas -Fata del Duce (Hechicera del Duce)-; el influyente New York Mirror, en un artículo dedicado a su embozado exilio, la menciona como "estrella conductora" y "zarina del arte fascista".

Esto es así porque casi todos los que han escrito sobre ella buscaron, para sus títulos, frases cortas que impactaran en el lector con expresiones metafóricas que, en pocas palabras, describieran la significación que tuvo en el firmamento fascista. Se trata de una mujer que aún hoy sigue dando que hablar. Si bien su existencia no encerró grandes misterios, las 
obras históricas sobre Mussolini y el fascismo todavía siguen sin tenerla demasiado en cuenta, lo cual facilita la construcción de ciertas leyendas que hacen hincapié en un grado de poder que no tuvo y en una relación sentimental que, como sostuvo De Felice, es imprecisable más allá del hecho indiscutible de haber acompañado a Mussolini en su trayectoria política.

Para Saviona Mane ese olvido no es casual. En una nota que titula en forma algo rimbombante, conforme a lo que vimos al comienzo, que ella utilizó: "The mother of fascism" (La madre del fascismo), alude a esa omisión o tal vez cierta premeditada indiferencia. Se trata de una entrevista hecha a la nieta de Margherita, Ippolita Gaetani, y en la que ésta, por esas ironías del destino, como olvidando la importancia de su abuela en la construcción del fascismo, proclama indirectamente su antisionismo, al atribuir actitudes fascistas a las autoridades israelíes. La autora sostiene, acertadamente, a nuestro juicio que:

"Todos en Italia quieren olvidar a la otra mujer del Duce: los fascistas porque era judía; sus oponentes, porque ella era fascista; y su familia, porque ella implica una carga histórica embarazosa. Consecuentemente concluye-su historia se escurrió de la conciencia pública y junto con ella su papel central en el fascismo italiano y en la vida del Duce.",1

¿Será la razón por la que importantes historiadores se ocupan poco de ella? Richard Bosworth, por ejemplo, quien ha escrito recientemente la que conocemos como una de las obras más voluminosas sobre Mussolini, relativiza expresamente su influencia y el papel público que cumplió aunque reconoce, sin priorizar lo sentimental, que la relación con

\footnotetext{
1 "Everyone in Italy wanted to forget the "Duce's other woman": the Fascists, because she was Jewish; their opponents, because she was Fascist; and the family, because she became an embarrassing historical burden. As a result, Margherita Sarfatti's story slipped out of the public awareness, and along with it her central role in Italian fascism and the Duce's life" (Haaretz)
} 
Mussolini fue política, cuando comenta que la "muerte sacrificial" de su hijo la reforzó pero que donde alcanzó prominencia fue en la política cultural del régimen (p. 112).

Analizar la diversidad de apelativos con los cuales se la denomina reviste importancia porque pone en evidencia ciertas diferencias en la valoración historiográfica que se derivan de las circunstancias apuntadas. No resultaría exagerado hacer una taxonomía de esas expresiones que, básicamente, corresponden a tres categorías: las de carácter político; las que se refieren a la relación sentimental, que por razones obvias son las que más impactan; y las que se vinculan con su papel intelectual, tanto ideológico como artístico. Con esa finalidad repasaremos a los pocos escritores de habla hispana que se han referido a Margherita Sarfatti.

El destacado intelectual español Francisco Ayala, durante su exilio en la Argentina, la conoció personalmente y escribió un artículo para el diario El País donde, con prudencia, reduce su influencia a la de "guía intelectual" y dirigente del ámbito cultural:

“...el papel de primer plano que hubo de desempeñar en el escenario histórico de nuestro siglo esta mujer inteligente, enérgica, refinada, ambiciosa, codiciosa y astuta que no sólo se erigió en la figura dirigente de la vida cultural italiana, sino que también fue la guía intelectual de Mussolini, cuyos escritos redactaba y cuyas decisiones trataba de manipular. "2

\footnotetext{
${ }^{2}$ Ayala, Francisco. Artículo en El País. 20 de setiembre de 1993. Se refiere al libro Il Duce's other woman, de Cannistraro y Sullivan que leyó con avidez porque recordó su encuentro con ella, como consecuencia de la cálida acogida a los escritores españoles exiliados que les dio la sociedad literaria argentina en la hospitalaria casa de Victoria Ocampo. Ayala hace un gran elogio de la obra de Cannistraro y Sullivan sosteniendo que se trata una biografía indispensable, tan minuciosa como rigurosa, de una bien lograda colaboración entre dos especialistas, además de ser un trabajo de estricta y muy controlada información, con datos concretos y debidamente documentados.
} 
Daniel Gutman, a su vez, escribió un libro de corte biográfico, de reciente aparición, donde realiza un minucioso examen de la correspondencia que ella mantuvo con importantes personalidades estadounidenses. Se trata de una obra excelente y de gran utilidad habida cuenta que, hasta donde conocemos, es el único libro escrito en español sobre Margherita Sarfatti y cuyo contenido, lamentablemente, no se corresponde con el título: El amor judío de Mussolini.

Y en la categoría de frases políticas contundentes, también el cineasta Tirri se valió de ellas cuando escribió desde Roma, para La Nación, un artículo que tituló "Reina sin corona” con una hipótesis novedosa acerca de su declinación política, en el que hace también agudas observaciones sobre las tendencias artísticas que cultivó.

\section{Aspectos biográficos relevantes}

Hablar de la italiana de origen hebreo Margherita Sarfatti, nacida en Venecia en 1880, priorizando su identidad italiana por sobre la hebrea, supone hacerlo también sobre la historia de "Gli ebrei d' Italia", porque de eso se trata. Los hebreos de esa nación fueron considerados más italianos que judíos y así es como Weizman, el dirigente sionista y primer presidente de Israel, después de observar las diferencias respecto de Europa Oriental, de donde provenía, expresó que en Italia no se daba ninguna de las razones que justificaron el sionismo puesto que los judíos estaban completamente amalgamados con el cuerpo de la nación y considerados por sus conciudadanos italianos al "ciento por ciento." (Michaelis, p. 215). En el libro que escribí sobre la temática ${ }^{3}$ desarrollé la opinión de algunas autores que analizan las causas que hicieron posible el alto grado de asimilación e integración social por parte de los judíos de Italia. Es por ello que diremos solamente que su situación constituyó una excepción al antisemitismo moderno, fenómeno o patrón de conducta por el cual los científicos sociales comprobaron, contra lo que todos suponían, que en los otros países de Europa la asimilación, como consecuencia de la emancipación

\footnotetext{
${ }^{3}$ El libro se titula "Italia y el antisemitismo" y en el mismo entre esas opiniones se destaca la de Andrew Canepa que entiende que ese alto grado de asimilación fue posible porque la unificación de Italia, lo que equivale al nacimiento de esa nación, fue simultánea con la emancipación de los hebreos, lo que hizo que no hubiera una nacionalidad preexistente que intentara prevalecer sobre la otra.
} 
política, lejos de disminuir el antisemitismo, lo estimulaba. Margherita Sarfatti fue un fiel exponente de esos hebreos integrados que, además, agregaba a esa condición identitaria su conversión al catolicismo y su decisión de abrazar el fascismo desde su comienzo.

Hija de una aristocrática y acaudalada familia de Venecia, tuvo una esmerada educación privada y desde muy joven demostró un interés especial por las letras y el arte. Su padre, Amedeo Grassini ${ }^{4}$, perteneció a la facción política liberal conservadora clerical y tuvo amistad con Giusseppe Sarto, quien posteriormente se convirtiera en Pío X gracias a su ayuda económica. Por la influencia de uno de sus profesores, Margherita estudió el marxismo y se convirtió, para disgusto de su familia, en una militante socialista que a los 14 años escribía notas con seudónimo para distintas publicaciones de ese signo.

Siendo muy joven, contrae matrimonio con Cesare Sarfatti, ${ }^{5}$ un abogado también socialista que incluso actuaba profesionalmente al servicio de esa causa. Se trasladan a Milán, donde ella comienza a trabajar, por recomendación de su marido, en el periódico Avanti, órgano oficial del partido. Allí conoce, en 1912, a su joven director Benito Mussolini y comienza entre ellos una relación profesional y política, como lo reconoce el propio Mussolini en el prólogo de Dux: "una comunidad de ideas y de trabajo". Según Gervaso, biógrafo de Claretta Petacci, comenzó compartiendo el amor por la cultura y por el "papel impreso" además de, naturalmente, las ideas políticas, y luego derivó en un romance que se iniciará en 1918, y "ninguna mujer, a excepción de Claretta, logró tenerlo tanto tiempo enamorado" (Gervaso, p.59).

La Primera Guerra Mundial les cambia la vida a ambos, a tal punto que sus ideas políticas sufren un vuelco copernicano. Mussolini es expulsado del partido socialista por intervencionista y resulta seriamente herido combatiendo en el frente. En el caso de Margherita Sarfatti, Roberto, su hijo mayor, de 17 años, muere en combate y la condecoración post mortem será lucida por ella en los actos patrióticos apropiándose, según

\footnotetext{
${ }^{4}$ Apellido que como muchos que llevaban los hebreos italianos se italianizaban a partir del hebreo, en este caso corresponde a la traducción de "Gerschom" que en hebreo significa el nombre de un hijo de Moisés, quién lo llamó así "Porque extranjero (Guer) fui en tierra extraña".

${ }^{5}$ Apellido gentilicio hebreo italianizado, que alude a su origen francés.
} 
su biógrafa Simona Urso, de ese trágico evento como medio de autopromoción (Parisini). Esta desgracia la acerca aún más al nacionalismo, que ya había comenzado a transitar al irse con Mussolini al nuevo periódico Il Poppolo d’Italia, donde según el comentario de Edvige, la hermana de Mussolini, fue la redactora más sensible a la borrachera nacionalista. Al margen de estas hipótesis especulativas, no puede descartarse que la muerte de su hijo le haya provocado ese estado de embriaguez. La carta que Roberto envía a sus padres cuando se dirige al frente debe haberla impactado profundamente: "La muerte encontrada combatiendo por el ideal de uno no es muerte, sino un paso al más allá. La sangre vertida por una idea, fructifica y pro Duce. Además, ¿Que tiene la muerte de tan terrible, como para uno deba temerla y odiarla como a una enemiga?" (Gutman, p.84).

Es importante que nos detengamos a considerar sus términos porque en ella puede rastrearse el germen de lo que será una de las características más importantes del fascismo: priorizar la acción por sobre las ideas, la glorificación de la guerra y un ardor patriótico que linda con lo patológico; la exaltación de la violencia como fin en sí misma. Se trata del mito de la violencia sustentada en lo que decía Marinetti, con su tristemente célebre frase: "La guerra única higiene del mundo". Todo ello se enlaza con la frase de Mussolini "vivir peligrosamente", inspirada en sus lecturas de Nietzsche y en las ideas de este filósofo sobre la paz como medio para nuevas guerras y la buena guerra como modo de santificación de toda causa.

De esa manera Margherita Sarfatti es testigo y protagonista de todo el proceso de formación del fascismo y más tarde, con la promulgación de las leyes raciales, se exilia voluntariamente. Durante la guerra vive alternativamente en Montevideo y Buenos Aires, donde fue muy conocida, para regresar en 1947 a Italia. Ya en su país natal se refugió, con muy bajo perfil, en Cavallasca, villa próxima a Como, donde muere en 1961.

\section{Valoración de su relación con el fascismo}

Hacer una evaluación del papel que le tocó jugar en el fascismo no es una tarea simple porque -como afirma Mane- no ocupó funciones oficiales de importancia ni tuvo 
responsabilidades partidarias. Además, su condición de mujer también puede haberla limitado, si bien, contra lo que suele pensarse y pese a la misoginia de Mussolini el rol de la mujer durante el fascismo fue bastante activo. ${ }^{6}$ El fascismo no fue totalmente desfavorable la situación de la mujer. Puede constatarse sin embargo el rechazo del fascismo por la posición de la izquierda, a la cual critica puesto que "sólo utiliza a la mujer como una imitación del hombre", y resulta ser "una tapadera de la fábrica del capitalismo industrial'. Esa conclusión se deriva del pensamiento fascista tradicional, que considera que el marxismo y el capitalismo han ido de la mano, y que ambos convierten a las mujeres en valores económicos. A esa concepción debe agregarse el pensamiento personal de Mussolini, ${ }^{7}$ quien no creía en la igualdad de aptitudes de los géneros y sostenía que la mujer estaba hecha para parir y obedecer. Consecuentemente, esa diferencia de funciones le vedaba el acceso a ciertos campos que se consideraban exclusivamente masculinos como la política, por ejemplo; no obstante, el socialismo ubicó a muchas mujeres en ese campo (De Felice, p.80) y se elogió cálidamente el patriotismo de mujeres combatientes (Ridley, p.418).

Respecto de la relación de Margherita Sarfatti con el fascismo, cabe preguntarse cuál fue entonces el aspecto más significativo del papel que jugó. Para percibirlo, y aunque resulte una cruel ironía, sirve revisar los aspectos dramáticos de dos intelectuales del fascismo que cuando cayeron en desgracia, sufrieron un gran desengaño, una especie de amor no correspondido con el fascismo: Margherita Sarfatti y Gino Arias. Ambos, fascistas sobresalientes, trataron de desprenderse de su "judeidad", en los términos de Arendt que sostuvo que algunos judíos quisieron escapar del judaísmo mediante la conversión, pero de la judeidad no hay escape posible (Hannah Arendt, p.141).

\footnotetext{
${ }^{6}$ Patricia Lenizan, que pertenece a la Fascist women union nos habla de ella de la siguiente manera: "Margherita Sarfatti, una Judía y líder del movimiento de arte Novecento, seguía siendo una autoridad principal en la cultura fascista, y revisó los principales puntos del fascismo"... "Para la Mujer fascista del próximo siglo, el significado de la vida está basado en la Maternidad, la lucha y la asistencia social (...) El fascismo sostiene que la mujer es el guardián natural de la fundación social y cultural de una Nación Hasta ahora el Fascismo es solamente una expresión masculina, cuando nuestros antagonistas exigen que la Mujer forme parte del Fascismo. Margherita Sarfatti, una judía y líder del movimiento de arte Novecento, seguía siendo una autoridad principal en la cultura fascista, y revisó los principales puntos de éste...” (Lenihan, Patricia; "Mujeres y fascismo").

${ }^{7}$ La misoginia personal de Mussolini se agudizó con el paso de los años: "Las mujeres compartían con los sacerdotes el hábito de tomarse el brazo cuando les daba un dedo". (Bosworth, p.258)
} 
Hemos traído a la cita a Arias porque vivió, quizá con más dramatismo que Margherita, su condición de intelectual expulsado del fascismo. Fue uno de sus cuadros más sólidos, porque fue el más importante teórico del corporativismo, que además se había convertido sinceramente al catolicismo al punto que en tal carácter participó de actividades organizadas por los sectores católicos más tradicionales. En Buenos Aires, disertó en unos cursos junto a importantes figuras de ese pensamiento, como Mario Amadeo, quien fue canciller de Lonardi y perteneciente a la derecha nacionalista. Ya exiliado por el fascismo, que lo destituye de sus cargos y cátedras, viene a la Argentina donde dictó clases en la Facultad de Ciencias Económicas de Córdoba (Argentina).

En lo que hace a Sarfatti, los motivos de su decepción surgen en una carta dirigida a su amigo Butler, presidente de la Universidad de Columbia de Nueva York, que Gutman transcribe en su obra y cuyos términos reproducimos:

“ ¿Es una Margherita triste y con el corazón roto la que te habla desde la desesperación de su alma...! Sabes lo que nos ha pasado. Soy católica, igual que mis dos hijos, ambos casados con católicos y padres de niños católicos. Pero yo, igual que mi esposo, soy descendiente de judios y en consecuencia tanto mis hijos como yo somos considerados judíos, el más aberrante pecado hoy en día. Se ha investigado nuestra ascendencia en tal medida que la gloriosa muerte de mi hijo en la guerra, como un héroe, a los 17 años, y la fe y el trabajo por el fascismo y por Italia de mi marido, de mis otros hijos y el mío propio no valen nada..." (Gutman, p.14).

Este autor destaca en el texto de contratapa su virtual caída en desgracia señalando:

"Que a pesar de fue considerada en su época de esplendor la mujer más poderosa de la Italia fascista. Ello no le sirvió porque después Mussolini no hizo nada por protegerla. Ansiosa por huir de una Europa donde se 
avecinaba la guerra, Margherita que en 1934 había sido recibida en la Casa Blanca por el presidente Roosevelt, intentó ingresar a los Estados Unidos, pero entonces ya se había transformado en un personaje indeseable, y ella que nunca había prestado atención a sus raíces se trasformó en una mujer judia”.

El dolor se hace más intenso aún al recordar que la muerte de Roberto tuvo el reconocimiento de Mussolini en términos tan conmovedores que tornan inimaginables que esa misma persona, veinte años después, se dedicara a perseguir gente como Roberto Sarfatti, nada más que por portar sangre hebrea. Para honrar su memoria públicamente, el Duce escribía en Il Popolo d'Italia:

“Hay - en verdad - algo de religioso, de poético, de profundo en el sacrifico de estos jóvenes. Deben cantar en sus almas la voz de la Patria, con acentos y ritmos ignotos (...) Un niño que debe ahora vivir, que apenas acaba de asomarse a la vida, que todavía no ha "tomado" nada de la vida, de todo: el presente y el futuro, lo que es y lo que podría haber llegado a ser. Hay algo que debe ser en él esa voluntad de renuncia que es el secreto y el privilegio de un gran amor",

Cuando reflexiona sobre el probable destino que tendrán sus obras escritas, Margherita expresa, con amarga ironía: "Encima mis libros ya no serán vendidos. Por lo que oí creo que serán quemados, junto con todos los libros italianos escritos por judíos en una ceremonia solemne, ;considerando que casi todos ellos fueron prologados por el propio Duce, suena como humor negro!...”. En la obra más resonante, relacionada con su

\footnotetext{
8 “C ${ }^{`} e ̀$ - in verità - qualche cosa di religioso, di poetico, di profondo nel sacrificio di questi giovani. Debe cantare nelle loro anime la voce della Patria, con accenti e ritmi che ci sono ignoti... Un fanciullo che debe ancora vivere, che si è appena affacciato alla vita, che non ha 'preso' ancora niente della vita, dà tutto: il presente e il futuro, ciò che è e ciò che avrebbe potuto diventare. $C$ 'è̀, ci devere essere in lui quella volontà 'di rinuncia che è il segreto e il privilegio di un grande amore" (Il Popolo d'Italia, 7 de febrero de 1918)
} 
biografía, el Duce expresa su complacencia: "Y este libro me gusta, porque me da proporciones en el tiempo, en el espacio y en los acontecimientos, sin hipertrofias a pesar de la amistad de la continuidad de trabajo y de ideas...". Margherita también debe haber recordado, con mucha pena y probablemente arrepentida, que entre los servicios prestados por su devoción al fascismo había declarado: "Mussolini en el nombre de Italia, ha tomado la jefatura del mundo; pero asume con ello una tarea más elevada aún, que es defender la civilización de la razas blancas" (Bosworth, p. 276). Tarde descubrió que el racismo equivale -como dijera Dujovne Ortiz- "al perro que se quiere morder la cola" o, como dijo Sartre, "todos somos judios respecto de alguien".

Después de sancionada la legislación racista y convencida de que no solamente ya no tenía espacio en la Italia fascista que ella había contribuido a crear, sino que seguir allí se tornaba peligroso, y pese a las gestiones de Mussolini para garantizarle seguridad, resuelve trasladarse a París en un doloroso y no reconocido exilio. Al ser Margherita Sarfatti un personaje altamente conocido en los ámbitos internacionales, no solamente por su actividad política sino por sus conferencias que, como políglota, pronunciaba en distintos países, en los idiomas de cada uno de ellos, la repercusión fue inmediata y un importante medio como el New York Mirror resaltó la magnitud de su trayectoria en una apretada y muy lograda semblanza biográfica:

“M. Sarfatti, alguna vez belleza veneciana, la judía de cabellos castaños rojizos que fue la estrella conductora del premier Mussolini durante su ascenso al poder, llegó aquí en misteriosa circunstancia, aparentemente vinculada a la campaña antisemita italiana y admitió que no puede servirse de las propiedades que le permitieron vivir como una líder social y una mecenas del arte. Esta mujer que fue la zarina del arte fascista que ha sido además de biógrafa de Mussolini la persona de mayor poder e influencia, se negó a discutir la campaña antisemita. (...) Ministros de Gabinete, Altos oficiales del Ejército y la armada y diplomáticos se inclinaban ante ella, 
porque era un secreto a voces que la suya, por encima de cualquier otra, era una voz escuchada por el Duce. Toda esa gloria comenzó a desvanecerse cuando ella desaprobó el gobierno Nazi en Alemania. Entonces, mientras la amistad de Mussolini e Hitler creció, aquella entre Mussolini y su asesora extra oficial se derrumbó..." (Gutman, p. 21)

Daniel Gutman destaca la protección que le brindaron, en la Argentina, Victoria Ocampo, Jorge Romero Brest o Emilio Petorutti en un espacio que era muy antifascista. La actividad cultural que desplegó en sus épocas de esplendor en Italia, concentrada en su famoso salón, la hizo conocida internacionalmente y la convirtió en una de las figuras señeras de la intelectualidad milanesa, cuya influencia será usada para difundir las ideas primigenias del fascismo y "blanquearlo" en sociedad. Esa actividad cultural y social nos recuerda a Rahel Varnhagen, la judía berlinesa, tan bien descripta por Hannah Arendt, que condujo otro de esos salones que solían ser regenteados por mujeres notables, y con frecuencia judías:

“El suyo era un salón frecuentado por la élite Italiana y también por la extranjera de paso. Margherita estaba en su cuarentena y era una mujer hermosa, sabía muy bien armar sus tertulias y poner en relación a sus invitados; sus reuniones eran siempre un éxito de animación y charme. Me encontraba allí con gente nueva y con los amigos que veía a menudo: Ada Negri Ungaretti, Folgore, Malerba, Buzzi, Marussig, Bontempelli, Sironi, Arturo Martin, Buggelli, Bucci, son algunos de los nombres que acuden a mi mente...”. (Gutman, p.55)

Frente a esos testimonios podemos decir que, si bien en algunos casos se ha sobredimensionado la magnitud de su ascendiente sobre el poder político, no se puede desconocer su importante rol. Recordemos, para corroborar esa afirmación, que el 
presidente Roosevelt la recibió, luego de leer un informe del embajador americano en Roma que la consideraba la mujer mejor informada de Italia para hablar de la situación política de ese país (Gutman, p.18). Hay que tener presente que en la mayoría de los dirigentes de los países más importantes la figura de Mussolini despertaba curiosidad, cuando no admiración, porque creían que había encontrado una síntesis superadora del capitalismo y el bolchevismo soviético. Esa imagen que ella fue a vender es la que compró Churchill en 1927, cuando afirmó: "si yo fuera italiano vestiría la camisa negra de los fascistas" y luego lo ratificó en una conferencia de prensa, al decir que en el caso de haber nacido en Italia habría estado plenamente con los fascistas y contra el leninismo (Hibbert, p. 33).

Si bien, según Luis Rossi, "la cultura no tuvo entidad propia en el fascismo, entendida como aquellas creaciones reconocidamente valiosas, más allá de su propio horizonte temporal y autónomas respecto de la política o la religión", en el campo de la difusión cultural artística su relevancia no está en cuestión. Es indudable el rol de Margherita Sarfatti como figura central en el mundo del arte en Italia y en el extranjero, especialmente debido al movimiento llamado "Novecento", por el que se intentó construir un lenguaje artístico original, hasta entonces en el surco de la tradición clásica. Convenció a Mussolini -según apunta Tremolada-, de que ese clasicismo debía moverse hacia una misión de "reinventar Roma". Ya vimos que De Felice tiene sus dudas en cuanto a esa acción persuasiva, pero reconoce que la "romanidad" la afectaba, utilizando una metáfora, en un grado casi patológico. Además la intensa actividad en los salones culturales no se limitó a esa función dado que, a veces, influyó también en lo político diplomático, como muy bien lo expresara el medio norteamericano.

Si atendemos a la dimensión política, considerada en su relación con el ejercicio del poder o la capacidad para imponer o torcer voluntades, los trabajos y las frases donde se le atribuía haber sido la mujer más poderosa caen en clichés y frases hechas, y tornan confuso el rol de la Sarfatti.

\footnotetext{
${ }^{9}$ Rossi pone como ejemplo a Luigi Pirandello, quien si bien fue fascista, mantuvo su producción ajena al movimiento, como lo estuvo por ejemplo la de Cesare Pavese, desde el antifacismo (Rossi, p.23).
} 
Entonces, ¿cuál fue su verdadera importancia? Para responder a ese interrogante hay que destacar que además de la influencia que sin duda tuvo en el campo de la cultura y el arte, fue testigo y partícipe de la creación del fascismo, ya desde su puesto al lado de Mussolini en la Piazza di San Sepolcro en el acto fundacional del fascismo. El valor simbólico de haber participado de ese acto fue ostentando orgullosamente por los fascistas con el nombre de "sansepolcrista", es decir, de la primera hora (De Felice, p.70). Incluso se le atribuye haber asesorado a Mussolini en la organización de la marcha sobre Roma y acerca de cómo tomar el poder.

Simona Urso afirma que recorrer la biografía intelectual de Margherita Sarfatti es importante, porque permite iluminar el hilo que teje algunas hipótesis sobre la génesis de la ideología fascista. Sostiene que este personaje mundano, vivaz e inquieto, participó activamente del debate político que atravesó la Italia giolittiana y que para ello absorbió nuevas sugerencias culturales por su frecuentación con el modernismo de los ambientes futuristas para trasladarlas a actitudes que confluyeron gradualmente a la posición intervencionista. $^{10}$

Pero una de las actividades en la que más se destacó fue la periodística, que le permitió estar muy cerca de la política. Colaboró con Mussolini en el Popolo d'Italia y desde esa función, contribuyó a limar la aristas más duras de Mussolini. Todavía se recuerdan sus crónicas de los viernes, en la tribuna del pensamiento de Sarfatti, indagando sobre las coordenadas de una estética fascista. En este sentido, Walter Benjamín sostiene que el fascismo trata de organizar las recién creadas masas proletarias sin afectar las estructuras de propiedad que las masas luchan por eliminar; en lugar de otorgarles sus derechos, les ofrece un modo de expresión y de preservar la propiedad mediante la introducción de la estética en la vida política. También asumió la codirección y luego, al asumir Mussolini como primer ministro, la dirección de la revista teórica del fascismo Gerarchia, que dirigió por una década (De Felice, p.228). Colaboró además en diversas publicaciones como La Stampa de

\footnotetext{
${ }^{10}$ Según la nota, ese pasaje sanciona el pasaje definitivo desde del reformismo uratiano, a través del culto de los caídos, que arribará a la ribera mitológica y por eso estuvo en el primer plano en la construcciones de un fascismo propio y el mito que se nutría plenamente de su propios rituales y códigos identitario. (Parisini, Roberto "Simona Urso del Dux al mito americano")
} 
Torino -donde escribieron los intelectuales más importantes del fascismo- desde donde contribuyó a difundir del mito del Duce. Todavía en el año 1934, cuando ya su fortuna política había empezado a escurrirse, siguió colaborando en la prensa haciendo de ghostwriter para Mussolini, en artículos que publicó en el New York Herald Tribune ${ }^{11}$. Incluso tuvo, hasta su pérdida de influencia, el control de la información a la prensa que tuviera relación con la imagen del Duce, especialmente, la que iba a los Estados Unidos (Tremolada).

Toda esa actividad periodística y literaria tuvo consumación máxima con la publicación de la biografía del Duce, traducida a 18 idiomas y con 17 reediciones, que trascendió los límites de los países europeos donde ya lo conocían. Este libro, titulado Dux, derivación de Duce, conductor, es el que le otorga mayor notoriedad y su objeto fue, fundamentalmente, difundir la imagen de Mussolini quien, además, escribió el prólogo. En cuanto a su contenido, Sarfatti elabora una construcción política de tal coherencia que en realidad, como lo demuestra la historia, Mussolini nunca tuvo y es importante en la idealización de los ritos y mitos de la sociedad. Se le atribuye haber elaborado el trato mesiánico que connotaba el fascismo con la utopía de un Estado nuevo mítico y una elite intelectual en la conducción de la nación ${ }^{12}$. Esto lo reconoce también Renzo De Felice, el máximo historiador del fascismo (De Felice. Mussolini il fascista... 371), autor de un trabajo de gran importancia documental histórica ${ }^{13}$, en cuya edición en español contó con un prólogo del intelectual español nacionalista Ernesto Giménez Caballero, con aspectos que merecen ser tenidos en cuenta en su biografía. Además, de sus términos surge una especie de premonición de lo que años más tarde constituyó una sólida alianza entre la Italia fascista y el bando nacionalista de la guerra civil.

\footnotetext{
11 "Nel '34 ancora collabora alla Stampa e continua a fare da ghostwriter per Mussolini che pubblica sul New York Herald Tribune, con la sua firma, articoli scritti dalla colta poliglotta che intanto progetta un viaggio negli Stati Uniti, a seguito del quale pubblicherà L'America". (Serri)

12 "Alla Sarfatti, Mussolini fu debitore anche dell'ideazione di riti e miti della società, con fez e gagliardetti, dal momento che proprio lei elaborò, nella sua fluviale produzione, il tratto messianico che connotava il fascismo e cioè l'utopia di uno Stato nuovo, di uno Stato-mito, con un'élite intellettuale alla guida della nazione. Dove pittori, artisti, scrittori e musicisti potessero avere un ruolo fondamentale, elaborando $i$ miti che sono alla base della comunità politica" (Serri)

${ }^{13}$ De Felice, Renzo. Mussolini il rivoluzionario- 1883-1922.
}

Cuadernos Judaicos - ISSN: 0718-8749

No 33 Diciembre 2016 
Al parecer, según Fermi, la idea de que escribiese sus memorias para el uso de los lectores de habla inglesa le fue brindada al Duce por su ferviente admirador Richard Wahsburn Child, embajador de los Estados Unidos en Italia de 1921 a 1924. La elección de la Sarfatti demuestra que reconocía talento en ella para una responsabilidad como ésa y se sintió complacido por la obra que había salido de su pluma (Fermi, p.326).

De esta manera, podemos afirmar que Margherita Sarfatti fue la principal artífice de la imagen de Mussolini, tan bien vendida luego por la propaganda fascista. Además, lo ayudó a afianzarse en la fase de la conversión intervencionista, y fue la primera en organizar su ideología, y en sistematizar el pensamiento mussoliniano. ${ }^{14}$ Sin embargo, Bobbio, cuando se refiere a los intelectuales más importantes del fascismo -menciona al filósofo Giovanni Gentile, al jurista Alfredo Rocco y al historiador Gioacchino Volpe- no menciona a Margherita Sarfatti (Bobbio, p.18). Es cierto que ella no escribió en la Enciclopedia Treccani, pero hay que tener en cuenta que esta es una creación de Gentile de 1925, cuando el fascismo ya estaba consolidado. También es posible que Bobbio no lo haya hecho para no subalternizar sus asépticos ensayos politológicos, contaminándolos con la consideración de una relación que trascendió lo político y que, como vimos, tanto se presta para el comentario fácil y ligero. Esa omisión podría deberse a que la influencia intelectual ideológica de Sarfatti fue más importante en el período de formación y en los primeros años del fascismo, porque cierto es que cuando éste ya se afianzó acudió a otros intelectuales con formación especializada. Además, ella ya había comenzado a ser hostigada por sectores decididamente antisemitas. De esta manera, en esa etapa, su actividad intelectual se limitó a sus actividades periodísticas y de asesoramiento, en muchos casos diplomático, como las que menciona Marcos Aguinis, cuando gracias a su intervención con el presidente Roosevelt Estados Unidos se negó a cumplir las sanciones a Italia por la invasión a Etiopía decretadas por la Sociedad de las Naciones.

Bobbio precisa que Gentile en 1925 ya había escrito "Qué es el fascismo", la voz relacionada con ese movimiento, en la Enciclopedia Treccani -en la que también colaboró

14 “...affiancò nella fase della conversione interventista, fu al suo fianco nell'atto della nascita del fascismo, fu la prima organizzatrice dell'ideologia mussoliniana, la prima sistematizzatrice del suo pensiero" (http://guide.dada.net/donne e arte/interventi/2006/12/280910.shtml) 
Rodolfo Mondolfo, también de origen hebreo - y que, además, en la tarea de la reforma de la instituciones intervino el jurista Alfredo Rocco, quien provenía del nacionalismo de derecha, y que contribuyó a la tarea más urgente que fue construir el régimen piedra por piedra. Al parecer, en esa tarea nada tuvo que ver Sarfatti y es probable que haya sido así. Pero como, por otro lado, el investigador menciona un artículo escrito por Mussolini en Gerarchia en 1923 (Bobbio, p.47), no puede haber desconocido la existencia de Sarfatti y es por eso que luce como llamativa la omisión, y mucho más aún cuando uno de los intelectuales que menciona, Volpe, también colaboraba en esa revista (Bostworth, p.209). No obstante todas las posibilidades analizadas, pensamos que si bien Bobbio atiende a los orígenes del fascismo para tratar de analizar sus nutrientes ideológicas, pone el acento, especialmente, en la consolidación del mismo con la creación de sus instituciones y en la versión histórica de aquéllos.

Lo concreto es que sus actividades, excluyendo la parte política en el sentido expuesto, son muy difíciles de categorizar, pero sus aptitudes le permitieron, como vimos, dispersarse en varios campos. Entre ellas, el papel intelectual fue el más fuerte, confirmando la opinión de Ayala al considerarla "guía intelectual". Quizá tampoco debemos ceñir esa influencia solamente a lo ideológico político y diplomático y olvidarnos de que, en sus comienzos, la misma se proyectó a lo social para mejorar la imagen de un Mussolini poco conocido. Fermi, en cierta manera y por el lado de Mussolini, confirma que éste presentaba ciertos síntomas de un complejo de inferioridad. En efecto, se sentía profundamente herido en su orgullo por no ser invitado al refinadísimo cenáculo de Anna Kuliscioff y tampoco al salón de Filippo Turati, el culto e inteligente jefe de los reformistas del socialismo, en el que se unía la flor y nata de la intelectualidad milanesa, y entre los hombres y mujeres de esa clase social, aparecía como un intruso y un advenedizo (Fermi, pp. 312-313).

En ese sentido, la profesora de la Universidad de Milán Ilaria Tremolada formula una hipótesis acerca de la naturaleza de la relación entre Sarfatti y Mussolini a la que consideró presidida por un afán especulativo por parte de ambos. $\mathrm{Su}$ razonamiento resulta más propio de un jurista que de un historiador por el manejo de lo que los especialistas en derecho probatorio denominan "prueba presuncional", y que consiste en que a partir de ciertos 
hechos históricos arriba a conclusiones que se internan en las motivaciones psicológicas de las personas. Así entiende que, al ser Margherita Sarfatti una de las más reputadas intelectuales de Italia dado que a su salón no solamente concurrían los artistas italianos, sino exponentes de la cultura internacional como Baker, Shaw, Cocteau y otros, utilizó ese prestigio para beneficio de la imagen de Mussolini, pero no lo hizo gratuitamente, sino para satisfacer sus ambiciones. El Duce, a su vez, tuvo buenos motivos para relacionarse con esta mujer dado que su proyecto necesitaba ser legitimado y aceptado, por lo que compartir esa ambición los llevó a una profunda complicidad. De esa manera, el rol de mayor importancia que quizá le tocó desempeñar fue el de legitimadora. Al mismo tiempo, para cumplir esa importante tarea en el "Milano bene", también debió suavizar al "tosco" caudillo y tratar de obtener el apoyo de la burguesía liberal, que esperaba grandes cambios con la guerra y buscaba una alternativa a la democracia débil e incapaz de afrontar la nueva dinámica, buscando convencerla de que Mussolini era el hombre justo en el momento justo. En otras palabras, Margherita le dio al fascismo la necesaria respetabilidad de la que la burguesía milanesa dudaba al observar el escuadrismo y la brutalidad de su líder (Tremolada). Para verificar esas conclusiones, sólo basta con observar la adhesión del senador liberal Albertini, que fue director del Corriere della Sera.

En cuanto a la personalidad ambiciosa de Margherita Sarfatti, existen suficientes testimonios que así lo revelan, entre ellos, nada menos que las expresiones confidenciales de Mussolini a la anarquista Leda Rafanelli, donde confiesa haber sufrido la profunda influencia de dos hebreas: la Balabanoff, “un alma noble y engañosa”, y la Sarfatti, "hermosa, pero con alma solapada, avara y sórdida" (Rafanelli, pp.50-51).

De todas maneras, las evidencias, al margen de las intenciones de ambos, revelan que esa función legitimadora se cumplió con óptimos resultados para el futuro Duce. 


\section{La cuestión identitaria: influencia de las raíces hebreas de Margherita Sarfatti en la génesis del fascismo}

Si, como vimos, Sarfatti tuvo un importante protagonismo tanto en la génesis del fascismo cuanto en la sistematización gradual de las ideas políticas que lo nutrieron, sobre todo en la concreción de un estado nuevo mítico y mesiánico, no podemos dejar de tratar la original interpretación que hace Simona Urso, que consiste en que pese a su asimilación y al hecho de haberse convertido al catolicismo, su raíces hebraicas le inspiraron la visión mesiánica del estado fascista. Como la identidad judía trasciende lo religioso, quizá sea ello lo que permite a la autora incursionar en esa línea interpretativa, dado que fundamenta la misma en que, no obstante su conversión religiosa, su "ebraísmo" seguía influyendo en ella como un potente resorte cultural. Al calificar como cultural a ese residuo identitario, pone a resguardo la posibilidad de que ese pensamiento se acerque, peligrosamente, al concepto de "judeidad" como un sino racial, del que nos habla Arendt. ${ }^{15}$

Así es que, como lo señala Löwy, muchos historiadores creen encontrar en las convicciones socialistas y revolucionarias de algunos judíos la expresión secularizada del mesianismo, bajo una forma atea o materialista de actitudes mentales heredadas de muchos milenios de tradición religiosa (Löwy, p.43). Ahora bien, tanto el marxismo como el anarquismo se encuentran en las antípodas del fascismo, sin perjuicio de los ingredientes de izquierda que pudieran haberlo integrado o influenciado, como así también la procedencia de ese origen de muchos fascistas entre ellos nada menos que Mussolini.

No obstante, hay que señalar algunos aspectos mesiánicos del fascismo y para emparentarlo con el que mesianismo judaico puede resultar instructivo la postura de Sánchez Albornoz en el debate identitario relacionado con las diferencias entre españoles y judíos. A la luz de esa discusión, la tesis de Simona Urso no resulta descabellada. El historiador español, cuando indaga sobre la cuestión identitaria para marcar las diferencias entre ambos pueblos, manifiesta un afán por encontrarlas en lo religioso y las remarca enfáticamente, mostrando

15 “...una nuova biografia mette in luce le sue radici ebraiche che le ispirarono una visione messianica dello stato fascista”. (La Stampa, 6 dicembre 2003) www.girodivite.it/article.php3 ?id_article=223-29k- 
la oposición existente entre la redención judía, de carácter colectivo, y la cristiana, de carácter individual, sostiene:

“Es difícil hallar nada más opuesto a lo auténtico español que estos rasgos esenciales de lo hispano judío. Frente al triunfo de lo social en el pensamiento religioso hispano-hebraico y en la vida misma de las comunidades hebreas se alza el híper individualismo hispano. El mesianismo hizo vivir a los judios peninsulares cara al mañana en una prolongada e ininterrumpida espera de un futuro luminoso y triunfador”. (Kuznitzky, 2006, p.104)

El concepto de redención o mesianismo colectivo, que invoca Sánchez Albornoz, vendría a ser lo que Simona Urso adjudica a las raíces judías de Sarfatti como un modo de contribuir a la concepción del Estado fascista. Como afirmara Arias -compañero de tribulaciones de Margherita- el individuo vive en una nación de la cual no es más que un elemento infinitesimal y pasajero; eso significa que, para la doctrina fascista, el valor de la persona humana se subordina a la preeminencia del estado, en una concepción corporativista. Desde luego, son más las diferencias existentes -sobre todo en los fines- habida cuenta la naturaleza religiosa de la redención judía, que esa mínima coincidencia relacionada con la identidad colectiva.

Ahora bien, nosotros albergamos ciertas dudas acerca de la existencia de rescoldos de identidad judía en Margherita, puesto que a ella le recordaron su judaísmo recién con la sanción con las leyes raciales. Lo señala muy bien Gutman; sólo en ese momento dictó conferencias sobre sus orígenes hebreos, mientras que anteriormente no les había otorgado ninguna importancia. Todas sus actitudes evidenciaron un afán por renegar de ese origen. 
Según el testimonio de Eleonora Smolensky ${ }^{16}$, no mantuvo ningún tipo de contacto con la colonia de calificados exiliados de judíos italianos en la Argentina.

Si existe una evidencia, no sólo de indiferencia hacia el judaísmo, sino también de su afán por ocultarlo, es el prólogo de la edición española de Dux del español de Ernesto Giménez Caballero. Este intelectual tan cercano al franquismo. Al aludir a Margherita Sarfatti, y no mencionar su origen hebreo; resulta evidente que el autor del prólogo lo desconocía y ella, por supuesto, no se encargó de recordárselo. Esta evidencia surge de la poética descripción física que realiza de ella, en el "Prólogo" a la edición argentina de la biografía de Mussolini escrita por Sarfatti, en la cual nada la vincula con los rasgos atribuibles a los judíos por Giménez Caballero en otros escritos. La describe como una mujer con pelo de fuego veneciano, de rubio veronés y piel de luna veneciana. ${ }^{17}$. Esta descripción no condice con lo que este español entendía desde el punto de vista étnico eran los judíos; un pueblo moreno.

Además, afirma que Margherita descendía de la nobleza aragonesa, cuando se sabe que, si bien es cierto que por la nobleza española corría mucha sangre judía, las mezclas se dieron con los judíos conversos y no con los públicos, quienes por eso, justamente, debieron exiliarse como el caso de los antepasados de ella. Resulta difícil imaginar que un linaje tan aristocrático, que por supuesto Margherita no tenía, haya sido invención de Giménez Caballero siendo altamente probable que ella lo invocara, precisamente para ocultar su identidad. Tampoco podemos imaginar a un franquista prodigando elogios a una personalidad de origen judía.

Ni siquiera podemos pensar en que ella pudiera ubicarse en la categoría de los "judíos no judíos" como los describe Isaac Deutcher, el biógrafo de Trostzky. En el sentido más general, los judíos se ubican en dos categorías: aquellos que se identifican a sí mismos como judíos, y aquellos que no se reconocen como tales. Estos últimos podrían ser calificados como "judíos no-judíos", un término acuñado por un judío radical, de

\footnotetext{
${ }^{16}$ En la presentación del libro de Daniel Gutman, en Buenos Aires, el 29 de marzo de 2007.

17 "Los arios rubios han necesitado siempre en sus empresas el complemento moreno. El ario inglés representante del espíritu de «libertad» necesitó de un pueblo moreno que coincidiese con esa idea de destrucción del continente. Y la encontró en el pueblo judío. (No por casualidad fue un judío-Disraeli- quien fundara el imperio inglés)". (Giménez Caballero)
} 
comienzos del siglo XX, Isaac Deutscher, para describirse a sí mismo. El "judío no-judío" es alguien que ha nacido de padres judíos pero que, aunque no es necesariamente hostil con los judíos, elige no identificarse ni con la comunidad ni con el judaísmo. No incluye entre los judíos no-judíos a aquellos que habiendo nacido judíos, se han convertido a otra religión, como el cristianismo (Deutscher, 1969).

No obstante, siempre moviéndonos en un plano meramente hipotético, y habiendo descartado la presunción identitario religiosa que sostiene Urso, pensamos que los afanes de redención mesiánica podrían haberle llegado Margherita por vía de su formación política de origen marxista, dado el planteo -según vimos- de identificación entre la redención mesiánica y la utopía libertaria , como si el judaísmo contuviera una esencia revolucionaria que consagraría lo que para Traverso se vería bajo el signo del concepto goethiano de afinidad electiva entre ambos conceptos ${ }^{18}$.

Sea como fuere, registrando o no su identidad judía en el sentido expresado, y pese a la falta de certidumbres históricas sobre ciertos aspectos de su actuación, con los existentes alcanzan para definir que su importancia en la génesis del fascismo, con un inconfundible sello colectivo o corporativo de preeminencia estatal en el marco de su relación con Mussolini, no fue menor y que lo sentimental, como afirmó Gianni Perona, fue lo secundario, de manera que prevalece su naturaleza política ${ }^{19}$.

A modo de conclusión podríamos señalar que una elemental taxonomía de la identidad judía, dividida entre que asumen su condición judía en alguna de sus dimensiones, tanto sea religiosa o laica; los "judíos no judíos" que como hemos visto no la asumen, pero no reniegan de sus orígenes e incluso reconocen aspectos de la misma en su formación;, y aquellos que siendo judíos de origen, desconocen el mismo y tratan de ocultarlo. Siendo ello así, Margherita Sarfatti por sus diversas actitudes, sobre todo por aceptar ese prólogo de Giménez Caballero, no solamente puso distancia con el judaísmo sino que trató, mientras pudo, de ocultar su origen. Su período de militancia socialista no la excusa,

\footnotetext{
${ }^{18}$ Traverso, p.7 y p.15 del prólogo de Pierre Vidal-Naquet.-

${ }^{19}$ Perona, Gianni (profesor titular de historia contemporánea de la Universidad de Torino). Conferencia sobre "El fascismo y los judíos", pronunciada en el Instituto Italiano de Cultura de Córdoba el 11 de junio de 2007.
} 
porque importantes personajes judíos de izquierda como es el caso de Trotzky, y el mismo Deutscher asumieron sus orígenes, para ubicarse en la mencionada categoría de los "judíos no judios", ni tampoco su posterior adhesión al fascismo lo explica porque en este movimiento en su génesis hubo nos pocos hebreos, al punto que según De Felice, eran más en proporción a lo que representaban en la población, que los italianos católicos, y además hubo corrientes de judaísmo expreso incorporadas al movimiento como es el caso de Ettore Ovazza que intentó fascistizar a toda la comunidad hebraica de Torino.

Como se expresó, pagó no pocos costos por una identidad no deseada, y tarde comprobó lo que vimos enseñara Arendt acerca de que de la judeidad no hay escape posible. O sea, una condena ontológica, dado que la persecución es "por ser" y no por adoptar determinadas conductas. Es la diferencia esencial entre la persecución racial y la política.

\section{Bibliografía}

Aguinis, Marcos. “El amor judío de Mussolini”. La Nación, 20/07/2007.

Arendt, Hannah. Orígenes de del totalitarismo. Madrid: Taurus, 1970.

Ayala, Francisco. Artículo en El País. "La otra mujer de Duce” 20 de setiembre de 1993.

Bedarride. Grandezas y Miserias de un Pueblo; Los Judíos en Francia, Italia y España. Ed. Victor Leru; Prólogo y traducción por Diego de Santillan; 1947.

Cristopher, Hibbert. Mussolini. Madrid: Ed. Librería editorial San Martín, 1972.

De Felice, Renzo. Entrevista sobre el fascismo. Buenos Aires: Ed. Sudamericana, 1979.

De Felice, Renzo. Il Duce, Lo Stato totalitario 1934- 1943. Torino: Einaudi; 1946. 
De Felice, Renzo. Mussolini el il fascismo. La conquista del estero. Torino: Ed. Einaudi.1996

Deutscher, Isaac. Los judíos no judíos. Buenos Aires: Ed Kikiyo, 1969.

Fermi, Laura. Mussolini. Mexico: Ed. Grijalbo, 1962.

Gervaso, Roberto. La amante de Mussolini. Buenos Aires: Ed. Abril, 1984.

Giménez Caballero, Ernesto. "La espiritualidad española y alemana”. La joven Europa, Berlín, 1942. "Prólogo" a la edición española de Sarfatti, Margherita. Mussolini. Bs. As: Ed. Juventud Argentina; Barcelona, 1940.

Gutman, Daniel. El amor judío de Mussolini. Bs.As.: Ed. Lumiere, 2006.

Hibbert, Christopher. Mussolini. Madrid: Ed. Librería editorial San Martín, 1972.

La Stampa. 6 dicembre 2003. www.girodivite. it/article.php3 ?id_article $=223$ - 29k Kuznitzky, Adolfo. La leyenda negra de España y los marranos. Córdoba: Ed. El Emporio, 2006.

Lenihan, Patricia. "Mujeres y fascismo". www.nuevoorden_19.html[JR1] (27 de mayo de 2006, imperio-secreto.blogspot.com/2006/05/la-noche-de-los-tecos.html)

Löwy, Michael. Redención y Utopía - El judaísmo libertario en Europa Central. Un estudio de afinidad electiva.. Ediciones El Cielo por Asalto. Buenos Aires. 1997

Michaelis, Mair. "Gli ebrei italiani sotto il regime fascista dalla marcia su Roma (1922 1945)”. La Rasegna Mensile di Israel. Roma, 1962.

Parisini, Roberto "Simona Urso del Dux al mito americano". http://www.rottanordovest.com/.Ed. MarzilioVenecia 2003. 
Perona, Gianni (profesor titular de historia contemporánea de la Universidad de Torino). Conferencia sobre "El fascismo y los judíos", pronunciada en el Instituto Italiano de Cultura de Córdoba el 11 de junio de 2007.

Rafanelli, Leda. Una donna e Mussolini.; Milano; Ed Rizzoli, 1946.

Rossi, Luis. "Introducción”. Bobbio, Norberto. Ensayos sobre el Fascismo. Bernal: Ed Prometeo y Universidad Nacional de Quilmes, 2006.

Sarfatti, Margherita. Mussolini. Prólogo de la edición española por Ernesto Giménez Caballero (El mundo y el Duce). Bs. As.: Ed. Juventud Argentina, Barcelona 1940.

Tasca, Angelo. El nacimiento del fascismo. Barcerlona: Ed. Critica, 2000.

Tirri, Néstor. La Nación. Buenos Aires: 26 de octubre de 2003.

Tremolada, Ilaria "La Donna che sgrezzò il 'bruto' Mussolini”. Storia in netbook http://www.archivioflaviobeninati.com/2013/03/la-madre-ebrea-del-fascismo-margheritasarfatti/.http://guide.dada.net/donne_e_arte/interventi/2006/12/280910.shtml 